\title{
1 A low cost approach to estimate demographic rates using inverse modeling
}

2 Roberto C. RodríGUeZ-CARO ${ }^{1 *}$, THORSTEN WIEGAND ${ }^{2}$, EASTON R. WHitE ${ }^{3}$, ANA SANZ-

3 AGUILAR ${ }^{1,4}$, ANDRÉS GIMÉNEZ ${ }^{1}$, EVA GRACIÁ ${ }^{1,3}$, JOSÉ D. ANADÓN ${ }^{5,6}$

$4 \quad{ }^{1}$ Ecology Area, Dept. Applied Biology. Miguel Hernández University - Av. de la Universidad.

5 Torreblanca, 03202, Elche, Spain

$6 \quad{ }^{2}$ Center for Population Biology. University of California Davis, 2320 Storer Hall. Davis CA

795616 California USA

$8 \quad{ }^{3}$ Department of Ecological Modeling, UFZ-Helmholtz Centre for Environmental Research, D-

904301 Leipzig, Germany

$10 \quad{ }^{4}$ Animal Demography and Ecology Group, IMEDEA (CSIC-UIB), Miquel Marquès 21, 07190

11 Esporles, Spain

$12{ }^{5}$ Department of Biology, Queens College, City University of New York. 65-30 Kissena Blvd,

13 Queens, Flushing, NY 11367 New York. USA

$14{ }^{5}$ The Graduate Center, Biology Program, City University of New York. $3655^{\text {th }}$ Ave, New York,

$15 \quad$ NY 10016 USA

16

17 (*) Corresponding author: r.rodriguez@umh.es

18 Running heading: Low cost method to estimate demographic rates 


\section{$1 \quad$ ABSTRACT}

2 Survival is a key parameter in species' management and conservation. Most methods for

3 estimating survival require time series data, large sample sizes and, overall, costly monitoring

4 efforts. Inverse modeling approaches can be less data hungry, however they are underused in

5 conservation sciences. Here we present an inverse modeling approach for estimating relative

6 survival rates of long-lived species that is mathematically straightforward and evaluate its

7 performance under constraints common in conservation studies related to small sample sizes.

8 Specifically, we (i) estimated the relative survival rates in a Testudo graeca population based on

9 one-year monitoring, (ii) assessed the impact of sample size on the accuracy, and (iii) tested

10 alternative hypotheses on the impact of fire on the survival rates. We then compared the results

11 of our approach with capture-recapture (CRC) estimates based on long-term monitoring. Our

12 approach (153 individuals within a single year) yielded estimates of survival rates overlapping

13 those of CRC estimates (11 years of data and 1009 individuals) for adults and subadults, but not

14 for juveniles. Simulation experiments showed that our method provides robust estimates if

15 sample size is above 100 individuals. The best models describing the impact of fire on survival

16 identified by our approach predicts a decrease in survival especially in hatchings and juvenile

17 individuals, similar to CRC estimates. Our work proves that inverse modeling can decrease the

18 cost for estimating demographic rates, especially for long-lived species and as such, its use

19 should be encouraged in conservation and management sciences.

20 Key words: Pattern-oriented model, survival rates, demography, tortoise, disturbance, fire,

21 Testudo graeca 


\section{INTRODUCTION}

24 The estimation of demographic parameters such as survival and reproduction rates is key for accurate forecasting of the fate of wildlife populations and for evaluating alternative management actions (Boyce, 1992; Williams et al., 2002; Beissinger and McCullough, 2002). In ecology, several approaches have been developed to estimate demographic parameters of wild animal and plant populations (Williams et al., 2002; Gross et al., 2002; Thomson et al., 2009). The estimation of age dependent survival is especially difficult for long-lived species because current methods such as capture-recapture (CRC) methods typically require long-term monitoring of individuals (Lebreton et al., 1992), which involves intensive field effort (e.g. for tortoises the range is 3-22 years monitoring, Appendix 1) and consideration of imperfect detection (Lebreton and Pradel, 2002; Thomas et al., 2010; Sanz-Aguilar et al., 2016). The capture-recapture framework allows for dealing with imperfect detection and is now commonly used to estimate animal survival rates (e.g., Lebreton et al., 1992; Lebreton and Pradel, 2002; Giménez et al., 2007; Thomson et al., 2009; Sanz-Aguilar et al., 2016). During the last decades, technological development has allowed to track animals and obtain direct survival estimates using telemetry data that provide an accurate monitoring of individuals over time (Millspaugh and Marzluff, 2001), but batteries do not usually last long (Bridge et al., 2011). Although CRC and telemetry monitoring methods proved to be accurate and useful, they can often not be applied for species of conservation concern where long-term studies would be very costly or infeasible (Williams et al., 2002).

An alternative to direct estimation of demographic parameters is indirect estimation based on population-level data such as age structure estimates (e.g., Caughley, 1977; Michod and Anderson, 1980; Udevitz and Ballachey, 1998; Wiegand et al., 2004). For example, survival 
rates can be indirectly estimated from age distribution data by analysis of the underlying agestructured Leslie matrix model if additional pieces of information are available, for example population growth rate, recruitment rates, the age structure of natural deaths, or stability of the age structure (Caughley, 1977; Michod and Anderson, 1980; Tait and Bunnell, 1980; Sickle et al., 1987; Udevitz and Ballachey, 1998). Similar methods were also developed in fisheries where catch-age patterns provide population age structures that then allowed together with auxiliary information for stock assessment (for a review see Quinn, 2003). These approaches fit into the pattern-oriented modeling strategy (Wiegand et al., 2003; Grimm et al., 2005), a general modeling framework that relies on "inverse modeling" where the outputs of a model called "patterns" (e.g., in our context the emerging stable age distribution of a population or time-series data) are used to estimate the model inputs (e.g., the unknown parameters). In other words, inverse modeling estimates parameter values by optimizing the match between observed patterns and the corresponding model outputs. Inverse modeling has been traditionally used in several scientific areas like hydrology, oceanography, soil science or climatology (Tarantola, 1987; Gottlieb and DuChateau, 1996; Wunsch, 1996; Bennett, 2002), but less in ecological studies. Exceptions are applications to time-series data (e.g., Wiegand et al., 1998, 2004; Gross et al., 2002; Martínez et al., 2011, 2016; González and Martorell, 2013; White et al., 2014; González et al., 2016; Zipkin et al., 2014a,b) or other types of patterns (e.g., Revilla et al., 2004; KramerSchadt et al., 2007; Hartig et al., 2011; Anadón, et al., 2012; May et al., 2015).

However, inverse modeling is still underused in ecology and, particularly, in conservation studies, and the performance of these methods under different sampling efforts and their potential for hypothesis testing or model selection have not been fully assessed. Here we present an inverse modeling approach for estimating relative survival rates of long-lived species that 
does not require long-term monitoring (or time-series data) and, as such, circumvents time and funding constraints commonly encountered in conservation studies. We illustrate our approach using the spur-thighed tortoise (Testudo graeca) in the southeastern Spain as a case study. This population has been intensely studied in previous studies (Pérez et al., 2002; Rodríguez-Caro et al., 2013, 2016, 2017), including long-term monitoring studies and capture-recapture studies (e.g. Sanz-Aguilar et al., 2011).

Our specific goals are threefold. First, we aim to compare estimates of survival rates of $T$. graeca obtained by means of our inverse modeling approach using age-distribution data from just one year with estimates obtained by means of capture-recapture methods using long term monitoring data (i.e. 11 years; Sanz-Aguilar et al., 2011). Second, we aim to explore how sample size affects the accuracy and precision of the estimated relative survival rates and to identify a minimum sample size for our case study. Third, we illustrate how our approach can be used to test alternative hypotheses on factors affecting survival, which is in our particular case study the impact of fire on survival rates. general flexible, our specific implementation relies on the assumptions that: a) the sampled population is stable and closed (i.e., no dispersal in or out of the study area); b) the observed age 
structure of the population contains signals of the demographic rates and detectability; and c) stochasticity is relatively unimportant.

First, an age-structured Leslie projection matrix (Caswell, 2001; Fig. 1b) is used to generate the expected stable age distribution (Fig. 1c) of hypothetical populations under different combinations of demographic parameters such as age-dependent survival rates $S_{i}$ and fecundity $F$ (Fig. 1a). To obtain the stable age distribution we used the R package popbio (Stubben and Milligan, 2007). To find the demographic parameters that produce the best match with the observed age structure (Fig. 1e), we varied them systematically over the parameter space (Fig. 1a) (Wiegand et al., 2004).

The age-structured Leslie transition matrix (A) takes the form

$$
A=\left[\begin{array}{cccccccc}
0 & 0 & 0 & \ldots & 0 & F_{r} & \ldots & F_{m} \\
S_{1} & 0 & 0 & \ldots & 0 & 0 & \ldots & 0 \\
0 & S_{2} & 0 & \ldots & 0 & 0 & \ldots & 0 \\
0 & 0 & S_{3} & \ldots & 0 & 0 & \ldots & 0 \\
0 & 0 & 0 & \ldots & 0 & 0 & \ldots & 0 \\
0 & 0 & 0 & \ldots & S_{r-1} & 0 & \ldots & 0 \\
0 & 0 & 0 & \ldots & 0 & S_{r} & \ldots & 0 \\
0 & 0 & 0 & \ldots & 0 & 0 & \ldots & 0 \\
0 & 0 & 0 & \ldots & 0 & 0 & \ldots & S_{m}
\end{array}\right]
$$

where the $S_{i}$ represent the survival rates for age $i=1$ to $m$, with $m$ being the maximal age, $r$ the age when subadults become adults (i.e., be reproductive), and $F_{i}$ the fecundity rate. Usually, the population is divided into $o$ different age classes (e.g., one-year-old individuals, juveniles, subadults, and for adults) and the same survival rates $S_{i}$ are assumed within each age class. The fecundity term varies depending on timing of the census (i.e., pre- or post-breading census). For the case of pre-breeding matrices as used here we obtain

$$
F=S R \times B S \times S_{\mathrm{h}}
$$


108 where $S R$ is the female sex ratio (note that the Leslie matrix is typically calculated only for

109 females), $B S$ the (age-independent) breeding success, and $S_{\mathrm{h}}$ is the survival from hatching to the

110 first year.

111 Given that individuals of the different age classes (e.g., juveniles vs. adults) can differ in

112 their detectability (e.g. Rodríguez-Caro et al., 2016, 2017), the predicted stable age distributions

113 must be corrected. This can be accomplished by multiplying the predicted age distributions

114 resulting from the projection matrix by age-dependent detection probabilities to obtain the

115 "observable age distribution" of the simulated populations.

116 Our inverse approach could be applied in principle for all parameters of the age-

117 structured Leslie transition matrix (eq. 1), however, because the effects of fecundity and

118 mortality parameters typically cancel in this type of models, parameter identifiability problems

119 may arise if no additional information is used (Wood, 1997). While survival parameters are

120 usually difficult to estimate on the short-term, fecundity parameters are more often available for

121 long-lived species such as the spur-thighed tortoise (Díaz-Paniagua et al., 1996, 1997). We

122 therefore applied inverse modeling for the relative survival rates of the age-structured Leslie

123 transition matrix (eq. 1) that are unknown, whereas we estimated age or stage-specific fecundity

124 from independent information.

125 We identified the relative survival rates that fitted the observed age distribution data best

126 by using a likelihood approach (Hilborn and Mangel, 1997; Burnham and Anderson, 2002). To

127 define the match between observed and predicted age distributions, we calculated the likelihood

128 of observing the observed age frequencies $\left(x_{1}, x_{2}, x_{3}, x_{4}, \ldots, x_{m}\right.$; where $m$ is the maximal age)

129 given the predicted age structure $\left(p_{1}, p_{2}, p_{3}, p_{4}, \ldots, p_{\mathrm{m}}\right)$ that emerged from a parameterizations $\boldsymbol{\theta}$ 
of the population model. Given the multinomial nature of our variable and assuming independence, the log-likelihood function is given by:

$$
l\left(\boldsymbol{\theta}, p_{1}, p_{2}, \ldots, p_{m}\right)=\log \left(\frac{n !}{\Pi x_{i} !}\right)+\sum_{i=1}^{m} x_{i} \log \left(p_{i}\right)
$$

where $n$ is the total number of individuals, $x_{i}(i=1, \ldots m)$ is the observed number of individuals in age class $i$ and $p_{i}(i=1, \ldots m)$ is the predicted proportion of individuals in age class $i$.

Because the stable age distribution $P$ is the right eigenvector of the dominant eigenvalue $\lambda$ of the Leslie transition matrix A (i.e., $\boldsymbol{A} P=\lambda P)$, multiplying the survival vector $\boldsymbol{\theta}=\left(S_{1}, \ldots, S_{o}\right)$ by a constant $c$ with $0<c<1 / \max (\boldsymbol{\theta})$ results in the same predicted stable age distribution and hence in the same likelihood. Therefore, we can identify only the relative survival rates $\boldsymbol{\theta}_{\text {rel }}=\left(S_{1} /\right.$ $S_{2}, S_{2} / S_{3}, \ldots S_{\mathrm{m}-1} / S_{\mathrm{m}}$ ), but use of additional information may allow us to restrict the range of the absolute survival rates.

There are different possibilities to find the maximum of the log-likelihood function over the parameter space; here we used an approach based on a rejection filter (e.g., Wiegand et al., 2004; Hartig et al., 2011) where we accepted in a first step all parameterizations $\boldsymbol{\theta}$ with $\Delta$ AIC $<2$ (Burnham and Anderson, 2002). We use the rejection filter approach to obtain the full posterior distribution of the relative survival rates $\boldsymbol{\theta}_{\text {rel }}$ and because we want to use the more flexible simulation approach to test alternative hypothesis on factors impacting survival (i.e., our third goal). However, as shortcut one may also fit the relative survival rates directly, for example using the mle function of stats4 package in R (R Core Team, 2016).

For each accepted parameterization $\boldsymbol{\theta}$ we calculated the ratios $S_{\mathrm{i}} / S_{\mathrm{i}+1}$ to obtain their posterior distribution. Because survival rates range between 0 and 1, the estimates of the relative survival rates allow us to generate upper bounds for each survival rate $S_{\mathrm{i}}$. To do this, we identify the highest survival rate in relations to each other, define its value as one, and obtain the 
corresponding values of the other survival rates as their upper bounds. In order to narrow down the possible range of the highest survival rate, we determine for different values of the highest survival rate the mean age of individuals that survived up to adult age the age only $1 \%$ of them reach and the longevity of the individuals (Castanet, 1994).

In theory, a population may reach a stable distribution, but in reality, it never arrives exactly at its stable distribution (Williams et al., 2011). It is thus critical to assess how far away a population is from the stable distribution. We therefore evaluated the distance between the observed age distribution and the stable age distribution of the best model using two common measures: Keyfitz's delta (Keifitz, 1968) and projection distance (Haridas and Tuljapurkar, 2007). Keyfitz's delta is the sum of the differences between the predicted stable age distribution and the observed age distribution and the projection distance is the difference between the reproductive value of a population with the observed age structure and the reproductive value of a population with the predicted stable age distribution.

Our approach can be extended to test alternative hypotheses on the drivers of temporal variation in demographic rates. To this end, different model structures that correspond to alternative hypotheses can be implemented within a simulation framework. For each alternative model structure, we determined the best estimate of the parameter vector $\boldsymbol{\theta}_{\text {rel }}$ using relative estimates and compared competing models structures based on their corresponding AIC values. Model structures with $\triangle \mathrm{AIC}<2$ were considered equally well supported (Burnham and Anderson, 2002).

\subsection{Case study}


We applied inverse modeling to estimate relative survival rates of a long-term monitored population of the endangered spur-thighed tortoise Testudo graeca. The spur-thighed tortoise is a small long-lived chelonian widely distributed in the Mediterranean basin. The "Cumbres de la Galera” population has been monitored during the last 15 years (Sanz-Aguilar et al., 2011; Anadón et al., 2012; Rodríguez-Caro et al., 2013, 2016). In summer of 2004, a fire burned 31\% of the study area. Sanz-Aguilar et al., (2011) and Rodríguez-Caro et al., (2013) estimated survival and the effect of fire on survival rates by means of multistate capture-recapture models and, by comparing the individual growth models, respectively. These survival estimates were used to validate the results of our inverse modeling approach.

We examined the observed age structure of the population in two different years: just before the fire event (2003) and 5 years later in 2009 (age distribution in Appendix 2) when the cumulative effects of fire over time are expected to be ceased (Sanz-Aguilar et al., 2011). We approximated individual age using growth rings and the carapace length (see details in Appendix 3). This allows us to distinguish in total twenty-five age classes. The oldest age class included all individuals older than 24 years because the accuracy of age estimations for older individuals in our population is low (Rodríguez-Caro et al. 2015). To compare our estimates of the survival rates with those obtained by classical capture-recapture methods, we classified 1 to 4 year old tortoises as juveniles $\left(S_{\mathrm{j}}\right)$, those aged 5 to 8 as subadults $\left(S_{\mathrm{s}}\right)$, and older individuals as adults $\left(S_{\mathrm{a}}\right)$ (Sanz-Aguilar et al., 2011). In addition we also included the survival from hatching to the first year $\left(S_{\mathrm{h}}\right)$. Our task is to find the best parameterization for our relative survival vector $\boldsymbol{\theta}_{\text {rel }}=\left(S_{\mathrm{h}} / S_{\mathrm{j}}\right.$, $\left.S_{\mathrm{j}} / S_{\mathrm{s}}, S_{\mathrm{s}} / S_{\mathrm{a}}\right)$

\subsection{Application (a): Estimating survival}


We applied our inverse approach to estimate the survival in our population using one year of monitoring (before the fire, 2003; $n=153$, Appendix 2). In a first step, we generated all possible parameterizations $\boldsymbol{\theta}=\left(S_{\mathrm{h}}, S_{\mathrm{j}}, S_{\mathrm{s}}, S_{\mathrm{a}}\right)$ where the ranges of each of survival rate $S_{\mathrm{i}}$ varied between 0.01 and 0.99 with steps of 0.02 , thus assuming a conservative upper bound for all survival rates of 0.99 . For each $S_{i}$ we therefore tested 50 alternative values. This resulted in a total of $50^{4}=$ $6,250,000$ parameter combinations. In a second step, we used a pre-breeding Leslie matrix with 25 age-classes (eq. 1), but survival rates were estimated per stage. The fecundity parameter of the Leslie matrix was defined by equation 2 , where first-year survival $\left(S_{\mathrm{h}}\right)$ was inversely determined by our approach, the sex ratio (SR) in this population was 0.5 (a clutch contains on average half male and half females) (Graciá et al., 2017), and breeding success was estimated as $B S=$ $N C \times C S \times H S=5.21$. For the latter we used data on the number of clutches $(N C=2)$ and clutch size $(C S=3.16)$, estimated in study by Rodríguez-Caro et al., (2014), and data on hatching success $(H S=0.824)$ was obtained from bibliography (Díaz-Paniagua at al., 1997).

In a third step, we obtained age-specific estimates of detectability by distance-sampling procedures (Thomas et al., 2010). Detection probabilities were 0.27 for juveniles (age 1-4), 0.41 for subadults (age 5-8) and 0.47 for adults (age > 8; see Appendix 4 for details).

In a fourth step, we calculated the likelihood (eq. 3) for each parameterization $\boldsymbol{\theta}$ using the corresponding detectability-corrected simulated age distribution (Fig. 1d) with the observed age distribution of the monitoring of 2003 (Fig. 1c), and accepted all parameterizations $\boldsymbol{\theta}$ with $\Delta$ AIC $<2$ (Burnham and Anderson, 2002). Next, we calculated for all accepted parameterizations the ratios $S_{\mathrm{h}} / S_{\mathrm{j}}, S_{\mathrm{j}} / S_{\mathrm{s}}$, and $S_{\mathrm{s}} / S_{\mathrm{a}}$ to obtain their posterior distribution and expected values, as well as the upper bounds of the survival rates. We also tested the difference between the observed age 
distribution and the stable age distribution (Williams et al., 2011). Finally, we compared our estimated survival rates with the mark-recapture estimates of Sanz-Aguilar et al., (2011).

\subsection{Application (b): Impact of sample size.}

By means of simulation experiments, we assessed the impact of sample size on the precision and accuracy of the relative survival estimates obtained by our approach. Starting from the stable age distribution resulting from a pre-breeding Leslie matrix with known parameter values $\hat{\boldsymbol{\theta}}$ (known vector of survival rates), we simulated a population of 1000 individuals by scaling the right eigenvector associated with the dominant eigenvalue (that represents the stable age distribution) to a total abundance of 1000 . We used the observed detection probabilities to obtain stochastic samples of the simulated population with different sizes $N$. The age distributions arising from this sampling process were then used in the same way as the observed data in our inverse modeling approach presented in Application 1. We repeated this procedure for different sample sizes $N(N=500,400,300,200,100,75,50,25)$. For each $N$, the sampling process was repeated 30 times. To select the minimum sample size that yields acceptable estimates we compared the increase of the standard deviation when reducing the sample size $N$. We tested the differences in the variance of the survival rates between $N=500$ and the other samples size by Levene's test (Levene, 1960).

\subsection{Application (c): Factors impacting survival}

Our approach also allows for testing alternative hypotheses on temporal variation in the survival and fecundity parameters of the Leslie matrix. We applied this feature to our case study by assessing the impact of a fire disturbance (that occurred in our population in 2004) on the 
8

59

60

temporal variation of the survival rates. This allowed us to compare our results with a previous study that estimated survival rates after fire by means of capture-recapture approaches (SanzAguilar et al., 2011) for the same population and disturbance.

We used the most likely model parameterization $\hat{\boldsymbol{\theta}}$ determined in Application 1 (that was based on the observed age distribution of the year 2003) to generate the stable age distribution for the year 2004 of the fire. We then simulated the next 5 years using survival rates modified in accordance with a set of alternative hypotheses and compared the simulated age distribution for year 2009 to the corresponding observed distribution (i.e. 5 years after the fire).

For hypothesis H0 (no effects of fire on survival), the survival parameters did not change, they are constant before and after the fire. For hypothesis H1, H2, H3, H4 and H5, population dynamics was simulated with new relative survival rates $\boldsymbol{\theta}_{\text {rel }}$ applied only for one, two, three, four or five years after the fire, whereas we applied in subsequent years the pre-fire survival rates $\hat{\boldsymbol{\theta}}$. The fire disturbance did not have negative effects on fecundity (Sanz-Aguilar et al., 2011), so we assumed no change in fecundity. We finally compared our estimates of thesurvival rates and the most likely hypothesis with that obtained in the previous study of Sanz-Aguilar et al., (2011).

\section{1. $\quad$ Estimating survival}

Our rejection filter retained 5001 out of a total of 6,250,000 tested parameter combinations $(0.08 \%)$. The relative survival rates were $\boldsymbol{\theta}_{\text {rel }}=(0.26,0.98,0.93)$ for $S_{\mathrm{h}} / S_{\mathrm{j}}, S_{\mathrm{j}} / S_{\mathrm{s}}$, and $S_{\mathrm{s}} / S_{\mathrm{a}}$ respectively (Fig. 2). The upper bound vector of survival rates was $\boldsymbol{\theta}_{\text {upper }}=(0.23,0.87,0.91$ 0.99 ) for $S_{\mathrm{h}}, S_{\mathrm{j}}, S_{\mathrm{s}}$ and $S_{\mathrm{a}}$, respectively. To assess a biologically reasonable lower and upper bound for adult survival $S_{a}$ (the highest survival rate). We found that a 9-year old individual reached for 
$S_{a}=0.85,0.9,0.95,0.97$, and 0.99 on average an age of $15,18,28,41$, and 106 years, and $1 \%$ of them reached at least an age of $37,52,98,160,467$ years, respectively. With a maximum longevity of the species in captivity reported as 102 years (Castanet, 1994), adult survival rates between 0.90 and 0.97 seem reasonable. In a second rejection filter, we selected the parametrization for hatching, juveniles and subadults using $S_{a}$ between $0.9-0.97$ (second rejection filter retained 1256) and we estimated the range for each survival rate $(0.17-0.33$ for $S_{h}, 0.71-0.99$ for $S_{j}$ and $0.75-0.97$ for $S_{s}$ ) (Fig. 3).

Sanz-Aguilar et al., (2011) estimated the survival rates of the population using 10 years of monitoring and obtained $\hat{\boldsymbol{\theta}}=(N A, 0.20,0.79,0.98)$ for juveniles, subadults and adults, respectively (Table 1) (note that $\mathrm{CRC}$ estimates did not consider first year survival). Our estimates for adult and subadult survival are very similar, with 95\% CI's overlapping that of Sanz-Aguilar et al., (2011) (Table 1). However, our estimates for juvenile survival differ from that of Sanz-Aguilar et al., (2011).

The measures of distance between observed and predicted age distribution showed that the population can be considered as stable. We found a value of Keyfitz's $\Delta=0.148$ and a projection distance $\alpha_{0}=-0.028$. A value of $\Delta=0.148$ means that just $14.8 \%$ of individuals are in other classes than expected (Keifitz, 1968). A projection distance $\alpha_{0}=0$ represent a stable age distribution, and our slightly negative value implies that the population is somewhat more concentrated into stages with low reproductive values. The stable age distribution is available in Appendix 2.

\subsection{Impact of sample size}



307 respectively.

308

309 Appendix 2.

Our estimates were robust for sample sizes larger than 100 individuals, but uncertainty increased quickly for smaller sample sizes (Fig. 4), especially for $S_{\mathrm{j}} / S_{\mathrm{s}}$. Within this range, the obtained estimates approximated the known survival rates well (Appendix 5). Below 100 individuals, estimates were more uncertain with larger standard deviations (Fig. 4). The Levene-test showed that the variance was different when the sample size was over or lower $100\left(W_{S h S j}=49.89, p\right.$ value $=<0.001 ; W_{S j S s}=55.16, p$-value $=<0.001 ; W_{S s S a}=55.57, p$-value $\left.=<0.001\right)$.

\subsection{Factors impacting survival}

The observed age distribution after the fire was calculated with 117 tortoises of year 2009 (Appendix 2). The hypotheses that received the least support were the null hypothesis H1 with no impact of fire on survival (Table 2). Hypothesis H5 that assumed more long-lasting effects of fire on survival (up to 5 years) represented the best model (Table 2). The estimate relative survival rates were $\boldsymbol{\theta}_{\text {rel H5 }}=(0.11,0.66,0.94)$. With the upper bound survival estimates $\boldsymbol{\theta}_{\text {upper H5 }}=$ $(0.07,0.62,0.94,0.99)$ for $S_{\mathrm{h}}, S_{\mathrm{j}}, S_{\mathrm{s}}$ and $S_{\mathrm{a}}$, respectively. We found a high reduction in one-yearold and juvenile survival after fire. Stable age distributions of the six hypotheses are available in

Our results partially match those obtained by Sanz-Aguilar et al., (2011) that also identified a large reduction in survival of young individuals. According to Sanz-Aguilar et al., (2011), after fire, survival rates were $0.11,0.62$ and 0.95 for juveniles, subadults and adults,

\section{DISCUSSION}


310 Survival is a key parameter in studies regarding the conservation of populations, and as such,

311 methods to estimate survival based on low sampling efforts are much needed. Approaches based

312 on inverse modeling have been proposed as a low cost method alternative to classic methods (i.e.

313 capture-recapture). However inverse modeling approaches are still underused in conservation

314 and management disciplines. Our study assesses the performance of these methods under

315 different sampling efforts and their potential for hypothesis testing.

\section{$317 \quad$ 4.1. Estimating survival}

318 Our comparison of the survival estimates from inverse modeling with that of capture-recapture is

319 insightful. Our estimates based on data of 153 individuals that were captured during one year of 320 monitoring are comparable to those obtained using capture-recapture analyses of 11 years (with $321>1000$ captures) in the same population. Our estimates agreed with capture-recapture estimates 322 for subadults and particularly adults, the age classes for which the species demography is more 323 sensitive (Doak et al., 1994; Walker et al., 2012; Pérez et al., 2012). However, as one may 324 expect, the uncertainty was somewhat higher when using only one year of data (Table 1). In our case, we directly estimate relative survival rates from the age distributions of 153 individuals captured during one year. However, biologically realistic values of survival rates (i.e.,

327 information on longevity) of the adult life stage were used as additional information to improve 328 parameter estimates.

The biggest difference in survival estimates between the capture-recapture method and 330 our approach appears in juvenile survival. However, we suspect that this difference emerged 331 largely because of methodological differences. Our approach divides juvenile survival into two groups: the first year and juveniles (until 4 years old), whereas the capture-recapture analysis 
could not consider first year survival separately because hatchlings were not marked (they have a soft carapace). Interestingly, our estimate of first year survival $\left(S_{\mathrm{h}}\right)$ is very similar to the capturerecapture estimate of juvenile survival $\left(S_{\mathrm{j}}\right)$ (Table 1). Additionally, the capture-recapture estimate of juvenile survival may be low because of the low detectability and sample size of young individuals (Doak et al., 1994; Hailey, 2000; Tuberville et al., 2008; Pike et al., 2008), because recapture probabilities of juveniles were not modeled separately, or because some juveniles may also lose the marks when growing carapace. However, beside of methodological differences, our approach may also overestimate juvenile survival because observed juvenile population sizes stay more or less equal from age 2 to age 4 (Fig. A2, Appendix 2). This effect can contribute to the unexpectedly high value of the juvenile survival. Clearly, stochastic effects can create this unusual pattern in juvenile age structure sizes because we used only one year of data and we have additionally considered a low detection probability of juveniles (27\%).

A previous study by Fernández-Chacón et al., (2011) on the sister tortoise T. hermanni that modeled recapture probabilities including age effects found a first-year survival rate of 0.39 (0.22-0.59) and an average of juvenile survival from age 1 to 4 years old of 0.69 . These estimates are similar to the rates obtained here for $T$. graeca. Our estimate of first-year survival rate (0.24) was also lower that the estimate by Keller et al., (1997) for the population of T. graeca in SW Spain (0.39). This difference could reflect actual differences between the two populations and suggest that overall survival of juveniles in our study area could be lower than in other populations. In the Doñana National Park, the predation of hatchlings has been described as very low (Keller et al., 1997), whereas in the population in the southeastern Spain predation rates are higher (García et al., 2003). 


\subsection{Impact of sample size on robustness of survival estimates}

357 The simulation exercise showed that survival estimates are robust provided samples sizes are

358 larger than 100 individuals. We observed a notable decrease in the precision and accuracy of the

359

estimates if the sample size was below 100 individuals. Moreover, our estimates were rather stable even with a low number of individuals. A sample size of 100 individuals from a single count or year represents a low sampling effort in comparison to the long-term monitoring effort usually needed in capture-recapture studies (in our study system, 11 years). Under what circumstances is this small decrease in the accuracy of the estimate acceptable? For many conservation efforts, where long-term monitoring programs are too expensive or infeasible, similar approaches as presented here will be extremely useful.

\subsection{Model selection and impact of fire on survival}

Our inverse-modeling approach was also successful in testing alternative hypotheses on factors affecting survival. We found evidence for a substantial decline of survival rates after the fire that lasted for several years. Our best supported hypothesis was H5, that predicted a 5 year effect after the fire and represents a long lasting effect of fire on survival. The capture-recapture study of Sanz-Aguilar et al., (2011), identified a faster recovery after the fire. As we did not estimate the recovery with our approach, we cannot compare in the same way both studies. However, both methods, with very different sampling efforts, identified the same general effects to describe the impact of fire on the survival of the different age classes. Both methods indicated that adult and subadult survival showed only a weak decrease after the fire. In contrast, our results suggest that juveniles and one-year-old tortoises suffered after the fire a notable decrease in survival.

However, because of the different predictions of juvenile survival, results of our method and of 
379 the capture-recapture estimates differed in the juvenile class. The ability of our approach to test

380 the support of alternative hypotheses on how different ecological processes influences

381 demography multiplies its usefulness and makes it more comparable to standard demographic

382 estimation methods in ecology and conservation.

\subsection{Accuracy vs. cost trade-offs}

385 Our results suggest that inverse modeling approaches provide a suitable framework for 386 estimating demographic rates and testing for its drivers (Gross et al., 2002, Zipkin et al., 2014a, 387 González et al., 2016). Overall, we found that estimates from inverse modeling were reasonably accurate when compared with the more data hungry capture-recapture analyses (with a sampling

389 effort ten times larger). However, it has to be noted that our approach uses not only the 390 population size structure extracted from the 2003 monitoring data, but also detection

391 probabilities (that were estimated from the same 153 individuals captured in 2003) and 392 independent information on sex ratio $(S R)$, number of clutches $(N C)$, clutch size $(C S)$, and 393 hatching success $(H S)$ to estimate the fecundity parameter $F$ of the Leslie matrix. The fecundity 394 parameters were estimated by radiography methods of females for 9 years (Rodríguez-Caro et al., 2014). Additionally, we used information on longevity to obtain reasonable bounds for adult 396 survival (information about longevity can be found in open database such us AnAge Database of 397 Animal Ageing and Longevity https://genomics.senescence.info/species/). As discussed above, 398 there is a trade-off between accuracy and cost: to what extent should we compromise our 399 conservation goals by trading accuracy in parameter estimates for costs? These trade-offs are 400 often poorly explored in conservation biology. It would be necessary to couple our approach 
401 with an optimization framework to inform on the trade-off between reduced cost vs. increased

402 reliability in the parameter estimates (Field et al., 2004, Wildermuth et al., 2013).

Application of our approach requires that (i) individuals can be aged reliably, (ii) the

404

405

406

407

408

409

410

411

412

413

414

415

416

417 418 term monitoring is not feasible. population should be assumed to be closed and stable (e.g., Keyfitz's $\Delta$ and the projection distance $\alpha_{0}$ to if the age distribution is stable; Williams et al., 2011), and (iii) the minimal number of individuals needed for this study is around 100. Moreover, a priori information of survival rates of particular age classes (e.g. adults) or the longevity of the species can be very useful for obtaining absolute estimates of survival rates. We presented here a simple and straightforward application of our approach that treats detectability and fecundity parameters as known, but focus on uncertainty in the unknown survival parameters. Extensions of our approach could adopt a Bayesian framework (e.g., Gross et al., 2002; Martínez et al., 2016) that considers also uncertainty in the estimates of fecundity parameters and a more complex observer model to describe detectability. However, such extensions would require more complex numerical optimization techniques for model parameterization. Future research should also consider the effects of stochasticity, especially at low population sizes, immigration and emigration, stagestructure populations and non-equilibrium dynamics. Overall, our work contributes towards broadening the toolbox in biodiversity conservation with a tool that is encouraged when long-

\section{Acknowledgements}

421 The Spanish Ministry of Science and European Regional Development Fund funded this work 422 through Projects CGL2012-33536 and CGL2015-64144; MINECIO/FEDER). We also wish to 
423 thank ACUDE for allowing us to work in its reserve and R. Salguero-Gomez for comments on 424 an earlier draft.

\section{References}

Anadón, J.D., Wiegand, T., Giménez, A., 2012. Individual-based movement models reveals sexbiased effects of landscape fragmentation on animal movement. Ecosphere 3: art64

Beissinger, S.R., McCullough, D.R., 2002. Population Viability Analysis. University of Chicago Press.

Bennett, A., 2002. Inverse Modeling of the Ocean and Atmosphere. Cambridge University Press Boyce, M.S., 1992. Population viability analysis. The Annual Review of Ecology, Evolution, and Systematics. 23, 481-506.

Bridge, E.S., Thorup, K., Bowlin, M.S., Chilson, P.B., Diehl, R.H., Fléron, R.W., Hartl, P., Kays, R., Kelly, J.F., Robinson, W.D., Wikelski, M., 2011. Technology on the move: recent and forthcoming innovations for tracking migratory birds. Bioscience 61:689-698

Burnham, K.P., Anderson, D.R., 2002. Model Selection and Multimodel Inference: A Practical Information-Theoretic Approach, 2nd ed. Springer-Verlag.

Castanet, J., 1994. Age estimation and longevity in reptiles. Gerontology, 40(2-4), 174-192.

Caswell, H., 2001. Matrix Population models, Second Edition. Sinauer Associates, Inc. Sunderland, MA.

Díaz-Paniagua, C., Keller, C., Andreu, A.C., 1996. Clutch frequency, egg and clutch characteristics, and nesting activity of spur-thighed tortoises, Testudo graeca, in southwestern Spain. Canadian Journal of Zoology, 74(3), 560-564. 
Díaz-Paniagua, C., Keller, C., Andreu, A.C., 1999. Hatching success, delay of emergence and hatchling biometry of the spur-thighed tortoise, Testudo graeca, in south-western Spain. Journal of Zoology, London 243:543-553

Doak, D.F., Kareiva, P., Kleptka, B., 1994. Modeling population viability for the desert tortoise in the western Mojave desert. Ecology Application 4, 446-460.

Duong, T., 2007. ks: Kernel density estimation and kernel discriminant analysis for multivariate data in R. Journal of Statistical Software, 21(7), 1-16.

Fernández-Chacón, A., Bertolero, A., Amengual, A., Tavecchia, G., Homar, V., Oro, D., 2011. Spatial heterogeneity in the effects of climate change on the population dynamics of a Mediterranean tortoise. Global Change Biology, 17(10), 3075-3088.

Field, S.A., Tyre, A.J., Jonzen, N., Rhodes, J.R., Possingham, H.P., 2004. Minimizing the cost of environmental management decisions by optimizing statistical thresholds. Ecology Letters, 7(8), 669-675.

García, C., Gorostiza, A., Ballestar, R., Yelo, N., Anadón, J.D., Pérez, I., Sánchez-Zapata, J.A., Botella, F., Giménez, A., 2003. Predation of the spur-thighed tortoise Testudo graeca by carnivorous fauna in Southeastern Spain. 2nd International Congress on chelonian conservation. Senegal.

Graciá, E., Rodríguez-Caro, R.C., Andreu, A. C., Fritz, U., Giménez, A., Botella, F., 2017. Human-mediated secondary contact of two tortoise lineages results in sex-biased introgression. Scientific reports, 7(1), 4019.

Giménez, O., Rossi, V., Choquet, R., Dehais, C., Doris, B., Varella, H., Vila, J.P., Pradel, R., 2007. State-space modelling of data on marked individuals. Ecological Modelling, 206, 431-438. 
González, E.J., Martorell, C., 2013. Reconstructing shifts in vital rates driven by long-term environment al change: a new demographic method based on readily available data. Ecology and Evolution, 3, 2273-2284.

González, E.J., Martorell, C., Bolker, B.M., 2016. Inverse estimation of integral projection model parameters using time series of population - level data. Methods in Ecology and Evolution, 7(2), 147-156.

Gottlieb, J., DuChateau, P., 1996. Parameter Identification and Inverse Problems in Hydrology, Geology and Ecology. Kluwer Academic Publishers, Dordrecht.

Grimm, V., Revilla, E., Berger, U., Jeltsch, F., Mooij, W.M., Railsback, S.F., Thulke, H., Weiner, J., Wiegand, T., DeAngelis, D.L., 2005. Pattern-oriented modeling of agentbased complex systems: lessons from ecology. Science, 310(5750), 987-991.

Gross, K., Craig, B.A., Hutchison, W.D., 2002. Bayesian Estimation of a Demographic Matrix Model from Stage-Frequency Data. Ecology, 83(12) 3285-3298.

Hailey, A., 2000. The effects of fire and mechanical habitat destruction on survival of the tortoise Testudo hermanni in northern Greece. Biological Conservation, 92, 321-333.

Haridas, C.V., Tuljapurkar, S., 2007. Time, transients and elasticity. Ecology Letters, 10, 11431153.

Hartig, F.J., Calabrese, B., Reineking, T., Wiegand, T., Huth, A., 2011. Statistical inference for stochastic simulations models - theory and application. Ecology Letters 14:816-827

Heppell, S.S., 1998. Application of life-history theory and population model analysis to turtle conservation. Copeia, 367-375

Hilborn, R., Mangel, M., 2002. The Ecological Detective. Confronting models with data. Monographs in Population Biology 28. Princeton University Press. 
491 Keyfitz, N., 1968. Introduction to the Mathematics of Populations. Addison-Wesley, Reading,

492

493

494

495

496

497

498

499

500

501

502

503

504

505

506

507

508

509

510

511

512

$$
\text { MA, USA. }
$$

Keller, C., Díaz-Paniagua, C., Andreu A.C., 1997. Postemergent field activity and growth rates of hatchling spurthighed tortoises, Testudo graeca. Canadian Journal of Zoology 75:1089-1098.

Kramer-Schadt, S., Revilla, E., Wiegand, T., Grimm, V., 2007. Patterns for parameters in simulation models. Ecological Modelling 204, 553-556

Lebreton, J.D., Burnham, K.P., Clobert, J., Anderson, D.R., 1992. Modeling survival and testing biological hypotheses using marked animals: a unified approach with case studies. Ecological Monographs 62:67-118.

Lebreton, J.D., Pradel, R., 2002. Multistate recapture models: modelling incomplete individual histories. Journal of Applied Statistics 29, 353-369.

Levene, H., 1961. Robust tests for equality of variances. Contributions to probability and statistics. Essays in honor of Harold Hotelling, 279-292.

Martínez, I., Wiegand, T., Camarero, J.J., Batllori, E., Gutiérrez, E., 2011. Elucidating demographic processes underlying tree line patterns: a novel approach to model selection for individual-based models using Bayesian methods and MCMC. American Naturalist 177: E136-E152

Martínez, I., González-Taboada, F., Naves, J., Fernández-Gil, A., Wiegand, T., 2016. Decline and recovery of a large carnivore: environmental change and long-term trends in an endangered brown bear population. Proceedings of the Royal Society of London B $\mathbf{2 8 3}$ art. 20161832 
May, F., Huth, A., Wiegand, T., 2015. Moving beyond abundance distributions - neutral theory and spatial patterns in a tropical forest. Proceedings of the Royal Society of London B 282: 20141657

Michod, R.E., Anderson, W.W., 1980. On calculating demographic parameters from age frequency data. Ecology, 61(2):265-269.

Millspaugh, J., Marzluff, J.M., 2001. Radio tracking and animal populations. Academic Press. Pérez, I., Giménez, A., Anadón, J.D., Martínez, M. and Esteve-Selma, M.Á., 2002. Patrones de actividad estacional y diaria de la tortuga mora (Testudo graeca L. 1758 ssp. graeca) en el sureste de la Península Ibérica. Anales de Biología, 4: 65-75).

Pérez, I., Tenza, A., Anadón, J.D., Martínez-Fernández, J., Pedreño, A., Giménez, A., 2012. Exurban sprawl increases the extinction probability of an endangered tortoise due to well-intentioned collections. Ecological Modelling, 245: 19-30.

Pike, D.A., Pizzatto, L., Pike, B.A., Shine, R., 2008. Estimating survival rates of uncatchable animals: the myth of high juvenile mortaility in reptiles. Ecology, 89, 607-611.

Quinn, T.J., 2003. Ruminations on the development and future of population dynamics models in fisheries. Natural resource modeling 16: 341-392

Revilla, E., Wiegand, T., Palomares, F., Ferreras, P., Delibes, M., 2004. Effects of matrix heterogeneity on animal dispersal: from individual behavior to metapopulation - level parameters. The American Naturalist, 164(5), E130-E153.

Rodríguez-Caro R.C., Graciá, E., Anadón, J.D., Giménez, A., 2013. Maintained effects of fire on individual growth and survival rates in a spur-thighed tortoise population. European Journal of Wildlife Research. 59: 911-913 
Rodríguez-Caro R.C., Graciá E., Anadón, J.D., Botella, P., Giménez, A., 2014. A compensatory response in reproduction of the tortoise Testudo graeca against habitat disturbances?. XIII Congreso Luso-Español de Herpetología. Aveiro (Portugal).

Rodríguez-Caro, R.C., Graciá, E, Morais Dos Santos, R. Anadón, J.D., Giménez, A., 2015. One scute ring per year in Testudo graeca? A novel method to identify ring deposition patterns in tortoises. Acta Herpetologica 10(2): 77-84

Rodríguez-Caro, R.C., Lima, M., Anadón, J.D., Graciá, E., Giménez, A., 2016. Density dependence, climate and fires determine population fluctuatios of the spur-thighed tortoise Testudo graeca. Journal of Zoology 300 (4), 265-273

Rodríguez-Caro, R.C., Oedekoven, C.S., Graciá, E., Anadón, J.D., Buckland, S.T., EsteveSelma, M.A., ..., Giménez, A., 2017. Low tortoise abundances in pine forest plantations in forest-shrubland transition areas. PloS one, 12(3), e0173485

Sanz-Aguilar A., Anadón J.D., Giménez A., Ballestar R., Graciá E., Oro D., 2011. Coexisting with fire: the case of the terrestrial tortoise Testudo graeca in mediterranean shrublands. Biological Conservation 144: 1040-1049.

Sanz-Aguilar, A., Igual, J.M., Oro, D., Genovart, M., Tavecchia, G., 2016. Estimating recruitment and survival in partially monitored populations. Journal of Applied Ecology 53: $73-82$.

Sickle, J.V., Attwell, C.A.M., Craig, G.C., 1987. Estimating population growth rate from an age distribution of natural deaths. The Journal of Wildlife Management, 51(4):941-948.

Stubben, C.J., Milligan, B.G., 2007. Estimating and Analyzing Demographic Models Using the popbio Package in R. Journal of Statistical Software 22:11. 
Tait, D., Bunnell, F., 1980. Estimating rate of increase from age at death. The Journal of Wildlife Management, 44(1):296-299.

Tarantola, A., 1987. Inverse Problem Theory: Methods for Data Fitting and Model Parameter Estimation. Elsevier, New York.

Thomas, L., Buckland, S.T., Rexstad, E.A., Laake, J.L., Strindberg, S., Hedley, S.L., Bishop, J.R., Marques, T.A., Burnham, K.P., 2010. Distance software: design and analysis of distance sampling surveys for estimating population size. Journal of Applied Ecology 47:5--14

Thomson, D.L., Cooch, E.G., Conroy M.J., 2009. Modeling demographic processes in marked populations. Springer, Berlin.

Tuberville, T.D., Norton, T.M., Todd, B.D., Spratt, J.S., 2008. Long-term apparent survival of translocated gopher tortoises: a comparison of newly released and previously established animals. Biological Conservation, 141, 2690-2697.

Udevitz, M.S., Ballachey, B.E., 1998. Estimating survival rates with age-structure data. The Journal of wildlife management, pages 779-792.

Walker, R.C.J., Whitmore, N., Rafeliarisoa, T.H., Hamylton, S., 2012. The effect of habitat deterioration on the long term survival of the Critically Endangered Madagascar spider tortoise. Biological Conservation 152, 152-158.

White, E.R., Nagy, J.D., Gruber S.H., 2014. Modeling the population dynamics of lemons sharks. Biology Direct 9: 23

Wiegand, T., Naves, J., Stephan, T., Fernandez, A., 1998. Assessing the risk of extinction for the brown bear (Ursus arctos) in the Cordillera Cantabrica, Spain. Ecological Monographs 68:539-571. 
Wiegand, T., Jeltsch, F., Hanski, I., Grimm, V., 2003. Using pattern-oriented modelling for revealing hidden information: a key for reconciling ecological theory and conservation practice. Oikos 100, 209-222.

Wiegand, T., Knauer, F., Kaczensky, P., Naves, J., 2004. Expansion of brown bears (Ursus arctos) into the eastern Alps: a spatially explicit population model. Biodiversity and Conservation 13, 79-114.

Wildermuth, R.P., Anadón, J.D., Gerber, L.R., 2013. Monitoring behavior: assessing population status with rapid behavioral assessment. Conservation Letters, 6(2), 86-97.

Williams, B.K., Nichols, J.D., Conroy, M.J., 2002. Analysis and management of animal populations. Academic Press, San Diego, California, USA.

Williams, J.L., Ellis, M.M., Bricker, M.C., Brodie, J.F., Parsons, E.W., 2011. Distance to stable stage distribution in plant populations and implications for near - term population projections. Journal of Ecology, 99(5), 1171-1178.

Wood, S.N., 1997. Inverse problems and structured-population dynamics. Pages 555-586 in S. Tuljapurkar and H. Caswell, editors. Structured-population models in marine, terrestrial, and freshwater systems. Chapman and Hall, New York, New York, USA.

Wunsch, C., 1996. The ocean circulation inverse problem. Cambridge University Press.

Zipkin, E.F., Sillett, T.S., Grant E.H.C., Chandler, R.B., Royle, J.A., 2014a. Inferences about population dynamics from count data using multistate models: a comparison to capturerecapture approaches. Ecology and Evolution 4(4): 417-426.

Zipkin, E.F., Thorson, J.T., See, K., Lynch, H.J., Grant, E.H.C., Kanno, Y., Chandler, R.B., Letcher, B.H.,. Royle J.A., 2014b. Modeling structured population dynamics using data from unmarked individuals. Ecology 95:22-29. 
a)
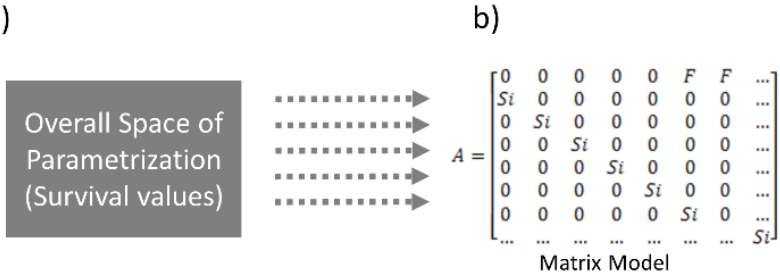

e)

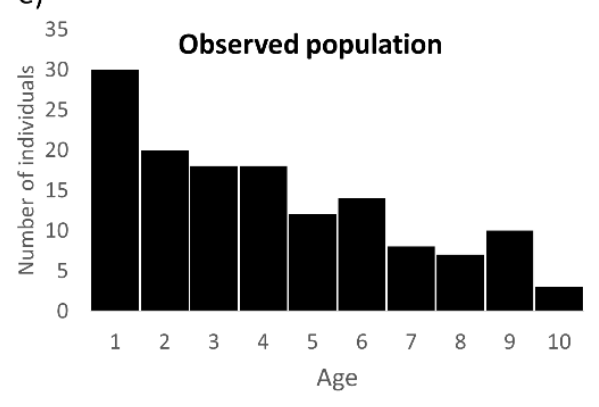

Comparing AIC of all

parametrizations

SELECT THE BEST

PARAMETERIZATION c)

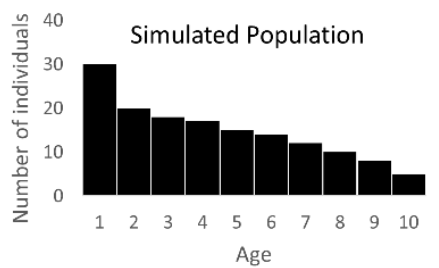

d) $\downarrow \downarrow \downarrow \downarrow \downarrow$ Detectability

40 Sampled Simulated Population

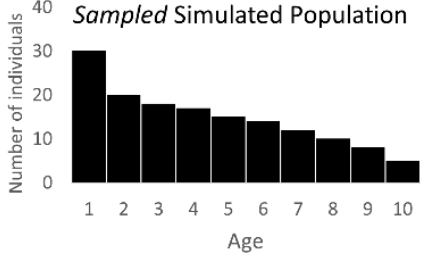

1

2 Figure 1. Summary of general framework of the model. 

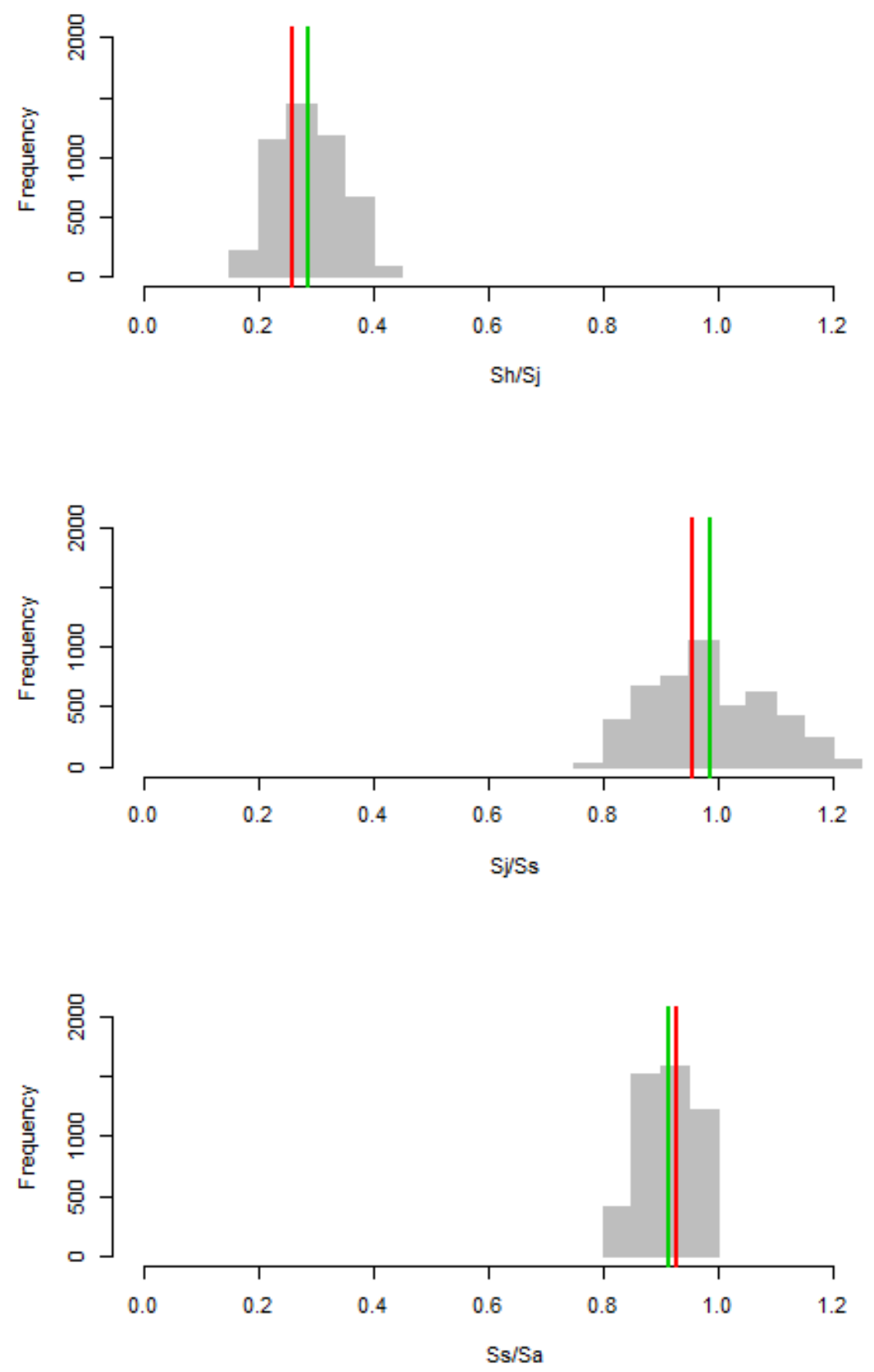

1

2 Figure 2. Histograms of the distribution of the relative survival rates $S_{\mathrm{h}} / S_{\mathrm{j}}$ (left) $S_{\mathrm{j}} / S_{\mathrm{s}}$ (middle) and

$3 S_{\mathrm{s}} / S_{\mathrm{a}}$ (right) for the 5001 parameterizations that yield $\Delta \mathrm{AIC}<2 . S_{\mathrm{h}}, S_{\mathrm{j}}, S_{\mathrm{s}}, S_{\mathrm{a}}$ are the survival rates

4 of hatchings, juveniles, subadults, and adults, respectively. The red lines are the maximum 
1 likelihood estimates of the relative survival rates and the green lines represent the average of the 2 distributions.
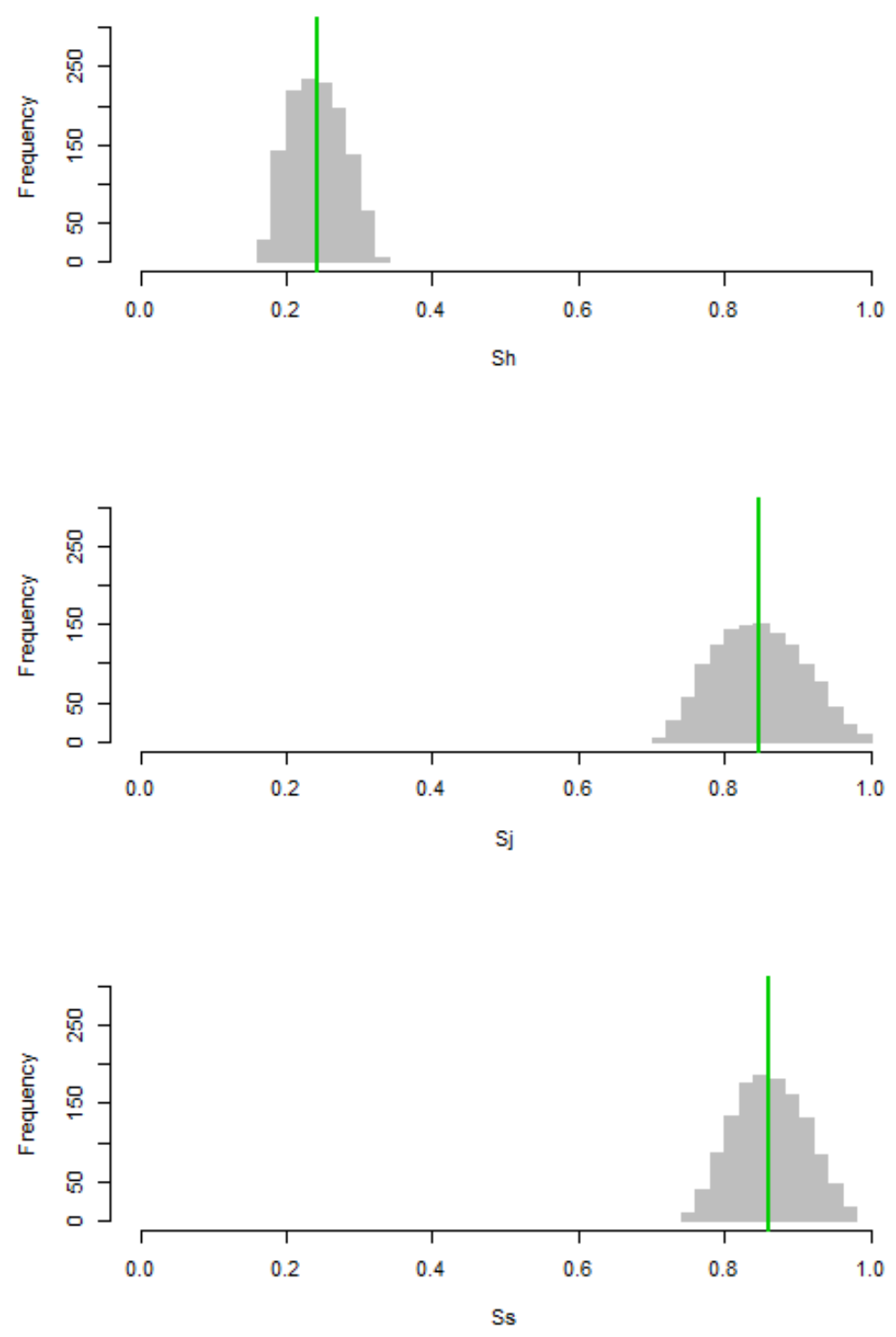

4

5 Figure 3. Histograms of the distribution of the absolute survival rates $S_{\mathrm{h}}$ of hatchings (left), $S_{\mathrm{j}}$ of

6 juveniles (middle), and $S_{\mathrm{s}}$ of subadults (right) for the 1256 parameterizations that yield $\Delta \mathrm{AIC}<2$

7 and where the adult survival rate $S_{a}$ was within the plausible range $(0.9,0.97)$. The green lines 
1 are the average values of the distributions. We obtain $S_{h}=0.24$ (range $17-0.33$ ), $S_{j}=0.85$

2 (range $0.71-0.99$ ) and $S_{S}=0.86$ (range $0.75-0.97$ ).

3

4 


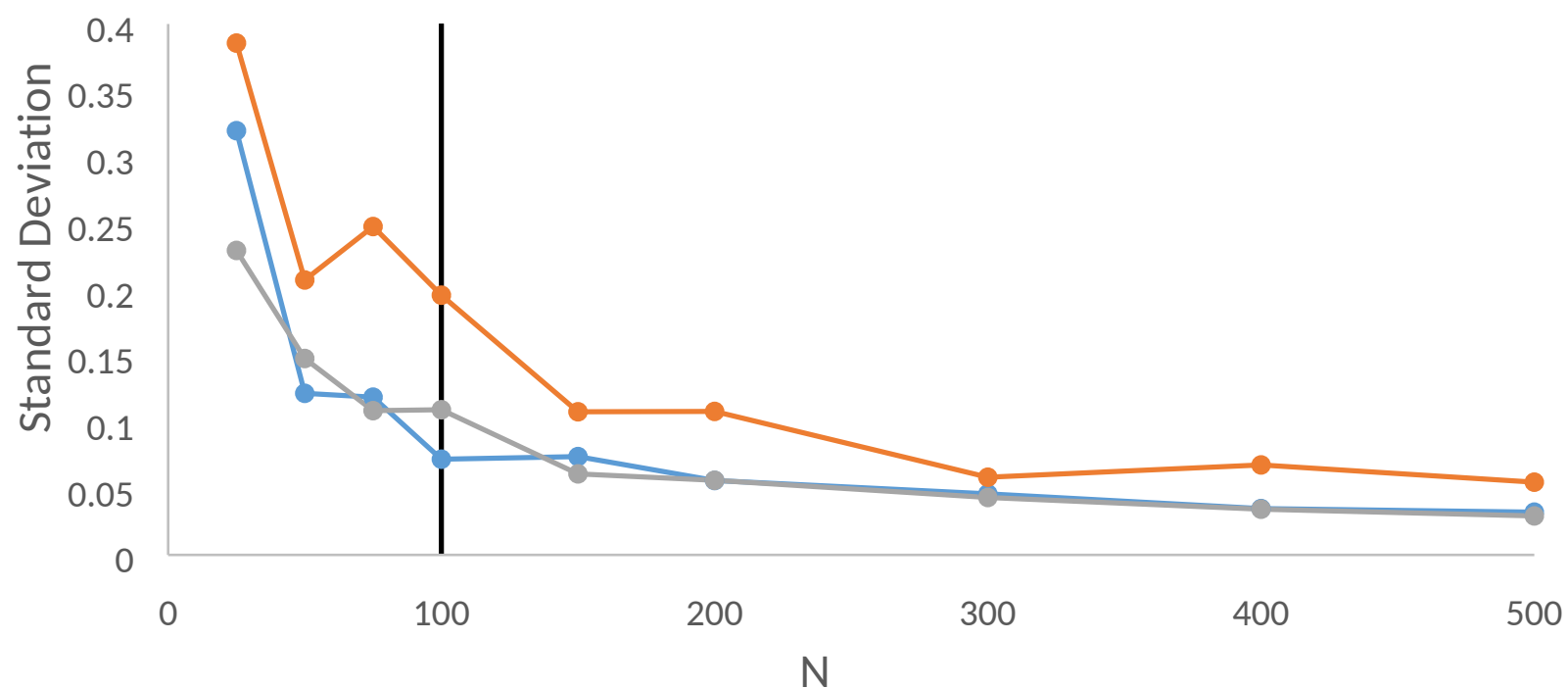

2

3

4

Figure 2. Reduction of the standard deviation (SD) through the increment of the sample size $(N)$ in the simulations (30 replicates) for $S_{h} / S_{j}$ in blue, $S_{j} / S_{s}$ in orange and $S_{s} / S_{a}$ in grey. When the sample size is lower than 100 the standard deviation increases substantially. 
1 Table 1 Range of survival rates estimated for one-year-old individuals, juveniles, subadults, and

2 adults $\left(S_{h}, S_{j}, S_{s} . S_{a}\right.$, respectively) and the mean estimates and $95 \%$ confidence interval calculated

3 by Sanz-Aguilar (2011). $N$ is the number of tortoises considered, the effort is the number of

4 hours searching for tortoises by person, and finally the period comprises the years of monitoring

5 used to collect data and reach the estimates.

\begin{tabular}{ccc}
\hline & Present study & Sanz-Aguilar et al., 2011 \\
\hline$S_{\mathrm{h}}$ & $0.17-0.33$ & - \\
$S_{\mathrm{j}}$ & $0.71-0.99$ & $0.20(0.08-0.42)$ \\
$\mathrm{S}_{\mathrm{s}}$ & $0.75-0.97$ & $0.79(0.57-0.90)$ \\
$S_{\mathrm{a}}$ & $0.90-0.97$ & $0.98(0.92-0.99)$ \\
$N$ & $173^{*}$ & $1389(675$ recaptures $)$ \\
Effort & 196 hours searching & 1600 hours searching \\
Period & 1 year (2003) & 11 years $(1999-2009)$
\end{tabular}

*173 tortoises found during the monitoring, but 20 discarded because were recaptures 
1 Table 2. Relative survival rates after the fire with the standard error and AIC for each

2 hypothesis. $\mathrm{H} 0$ represent no effect of fire, the relative survival rates were the rates estimates in

3 Application 1, $\mathrm{H} 1, \mathrm{H} 2, \mathrm{H} 3, \mathrm{H} 4$ and $\mathrm{H} 5$, represent the maintained effect of fire of one, two, three,

4 four and five years, respectively. In bold the best model according AIC selection.

\begin{tabular}{ccccc}
\hline Hypothesis & $S_{\mathrm{h}} / S_{\mathrm{j}}$ & $S_{\mathrm{j}} / S_{\mathrm{s}}$ & $S_{\mathrm{s}} / S_{\mathrm{a}}$ & AIC \\
\hline H0 & 0.260 & 0.957 & 0.928 & 157.54 \\
H1 & $0.07(0.04)$ & $0.71(0.20)$ & $1.07(0.26)$ & 148.36 \\
H2 & $0.07(0.04)$ & $0.72(0.12)$ & $1.01(0.13)$ & 140.05 \\
H3 & $0.06(0.03)$ & $0.71(0.09)$ & $0.97(0.08)$ & 122.40 \\
H4 & $0.11(0.03)$ & $0.68(0.08)$ & $0.96(0.07)$ & 115.15 \\
H5 & $\mathbf{0 . 1 1 ( 0 . 0 3 )}$ & $\mathbf{0 . 6 6 ( 0 . 0 8 )}$ & $\mathbf{0 . 9 5 ( \mathbf { 0 . 0 6 } )}$ & $\mathbf{9 8 . 3 5}$
\end{tabular}

5

6

7 
2 Table A1.1. Sample size and time of monitoring of several species of terrestial tortoises

3 to estimate survival by capture-recapture methods. Time is the length of study and $\mathrm{N}$ is

4 the sample size.

\begin{tabular}{lcccl}
\hline Species & Time & N & Place & Citation \\
\hline Astrochelys yniphora & 8 years & 329 & Madagascar & O'Brien et al. 2005 \\
Gopherus agassizii & 10 years & 531 & EEUU & Lovich et al. 2014 \\
Gopherus berlandieri & 10 years & 2128 & EEUU & Kazmaier et al. 2001 \\
Gopherus morafkai & 22 years & $1186^{*}$ & EEUU & Zylstra et al. 2012 \\
Gopherus popyphemus & 5 - 11 years & 1667 & EEUU & Tuberville et al. 2014 \\
Homopus signatus & 5 years & 237 & South Africa & Loehr 2010 \\
Pyxis arachnoides & 3 years & 404 & Madagascar & Walker et al. 2012 \\
Teatudo graeca & 11 years & 1389 & Spain & Sanz-Aguilar et al. 2011 \\
& & & & Bertolero et al. 2007 and \\
& & & & Fernández-Chacón et al \\
Testudo hermanni & 18 years & 361 & Spain & 2011 \\
Testudo hermanni & 9 years & 6565 & Greece & Hailey 2000 \\
Testudo hermanni & 7 years & 401 & France & Henry et al. 1998 \\
\hline
\end{tabular}

$* \mathrm{~N}$ of marked individuals

\section{$7 \quad$ References}

8 Bertolero, A., Oro, D., \& Besnard, A. (2007). Assessing the efficacy of reintroduction

9 programmes by modelling adult survival: the example of Hermann's tortoise. Animal

10 Conservation, 10(3), 360-368.

11 Fernández-Chacón, A., Bertolero, A., Amengual, A., Tavecchia, G., Homar, V., \& Oro,

12 D. (2011). Spatial heterogeneity in the effects of climate change on the population

13 dynamics of a Mediterranean tortoise. Global Change Biology, 17(10), 3075-3088.

14 Hailey, A. (2000). The effects of fire and mechanical habitat destruction on survival of

15 the tortoise Testudo hermanni in northern Greece. Biological conservation, 92(3), 32116333. 
17 Henry, P. Y., Nougarède, J. P., Pradel, R., \& Cheylan, M. (1999). Survival rates and demography of the Hermann's tortoise Testudo hermanni in Corsica, France. Current studies in herpetology, 189-196.

Kazmaier, R. T., Hellgren, E. C., Synatzske, D. R., \& Rutledge, J. C. (2001). Mark-

21 recapture analysis of population parameters in a Texas tortoise (Gopherus berlandieri) 22 population in southern Texas. Journal of Herpetology, 410-417.

23 Loehr, V. J. (2010). Structure and dynamics of a Namaqualand speckled tortoise 24 (Homopus signatus signatus) population over 5 years of rainfall variation. Chelonian 25 Conservation and Biology, 9(2), 223-230.

26 Lovich, J. E., Yackulic, C. B., Freilich, J., Agha, M., Austin, M., Meyer, K. P., ... \& Root, 27 S. A. (2014). Climatic variation and tortoise survival: Has a desert species met its 28 match?. Biological Conservation, 169, 214-224.

29 O'Brien, S., Robert, B., \& Tiandry, H. (2005). Consequences of violating the recapture 30 duration assumption of mark-recapture models: a test using simulated and empirical data 31 from an endangered tortoise population. Journal of Applied Ecology, 42(6), 1096-1104. 32 Tuberville, T. D., Todd, B. D., Hermann, S. M., Michener, W. K., \& Guyer, C. (2014). 33 Survival, demography, and growth of gopher tortoises (Gopherus polyphemus) from three 34 study sites with different management histories. The Journal of Wildlife 35 Management, 78(7), 1151-1160.

36 Zylstra, E. R., Steidl, R. J., Jones, C. A., \& Averill-Murray, R. C. (2013). Spatial and 37 temporal variation in survival of a rare reptile: a 22-year study of Sonoran desert 38 tortoises. Oecologia, 173(1), 107-116. 
$2 \mathbf{2 0 0 3}$

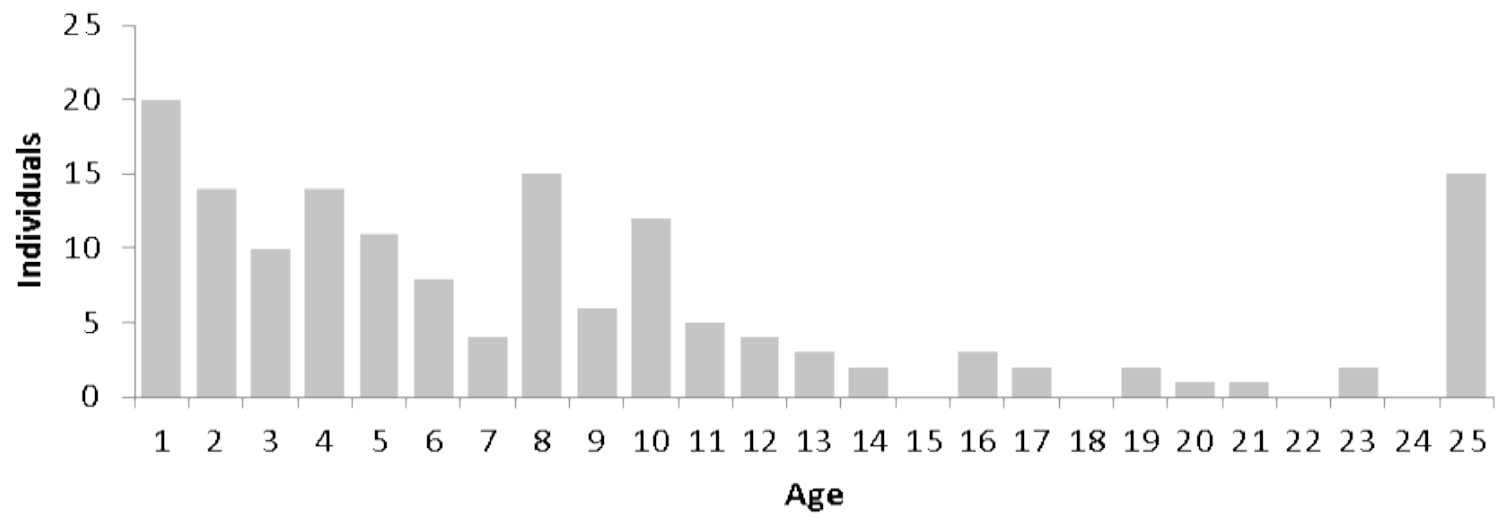

3

$4 \quad 2009$

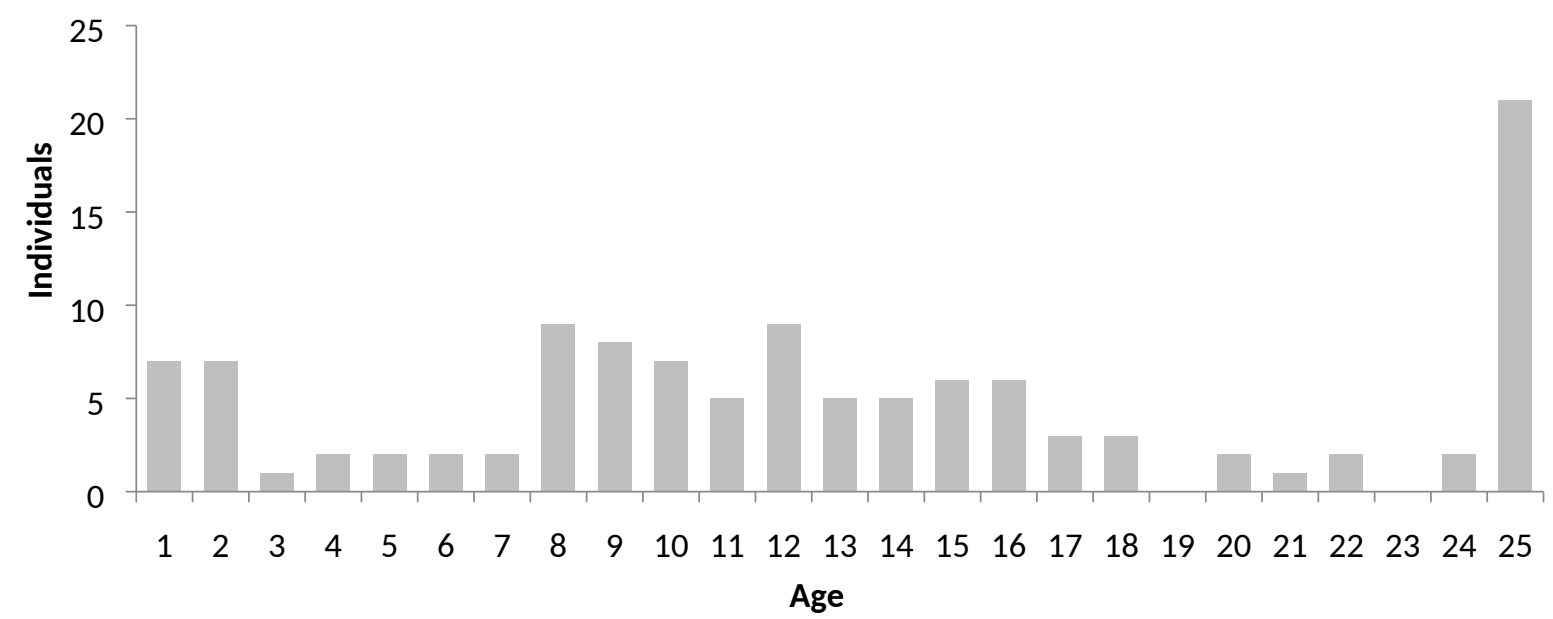

5

6 Figure A2.1. Age distribution of the population in 2003 and 2009, before and after the

7 disturbance. $N=153$ and $\mathrm{N}=117$, respectively 


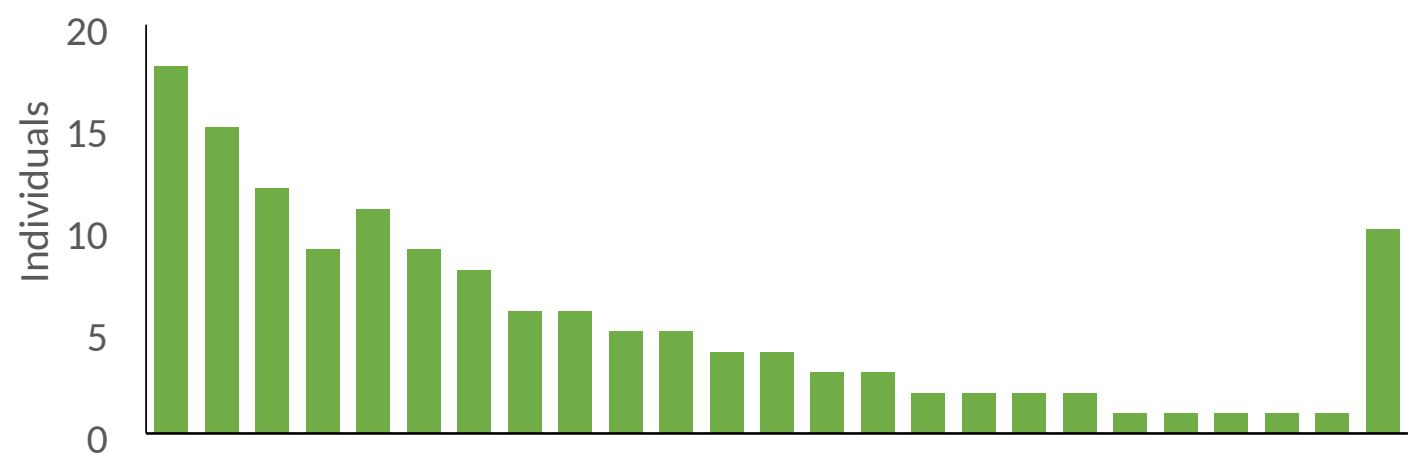

$122 \quad 3 \quad 4 \quad 5 \quad 6 \quad 7 \quad 8 \quad 910111213141516171819202122232425$ Age

10

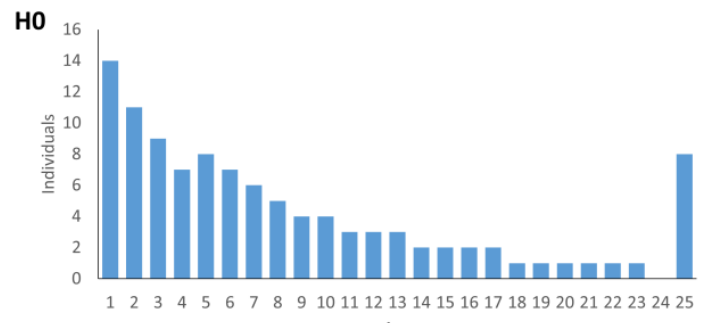

H1

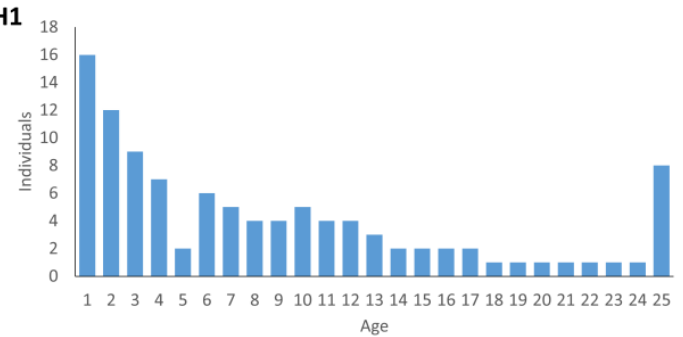

$\mathrm{H} 2$

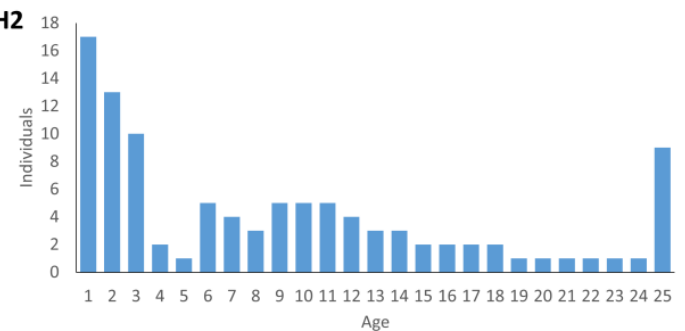

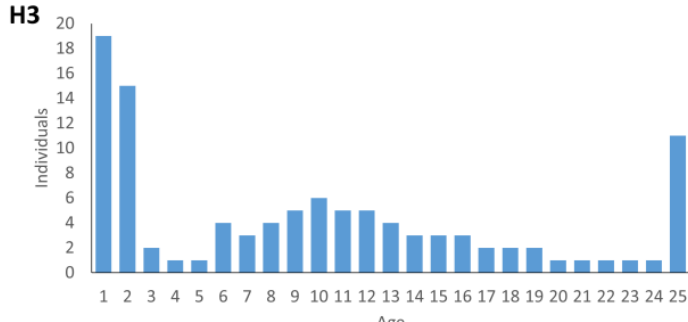

Age
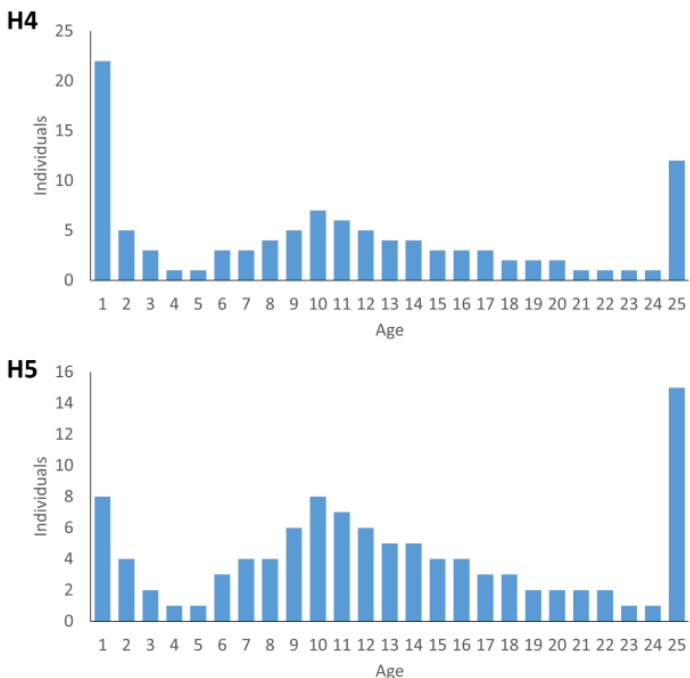

12

13 Figure A2.2. . Stable age distribution of the population in 2003 according to the model

14 and simulated age distribution in 2009 for the 6 hypothesis. H0 represent no effect of

15 fire; $\mathrm{H} 1, \mathrm{H} 2, \mathrm{H} 3, \mathrm{H} 4$ and $\mathrm{H} 5$, represent the maintained effect of fire of one, two, three,

16 four and five years, respectively. 
2 We estimate the age of the individuals using two methods; 1) counting de number of rings

3 (Rodríguez-Caro et al. 2015) and measuring the carapace length (Rodríguez-Caro et al.

4 2013).

5 The method of counting growth rings was described in Rodríguez-Caro et al. (2015). We

6 used this method for tortoises aged up to 10 years old, the period in which counting 7 growth rings is plausible.

\section{$\mathrm{CL}$}

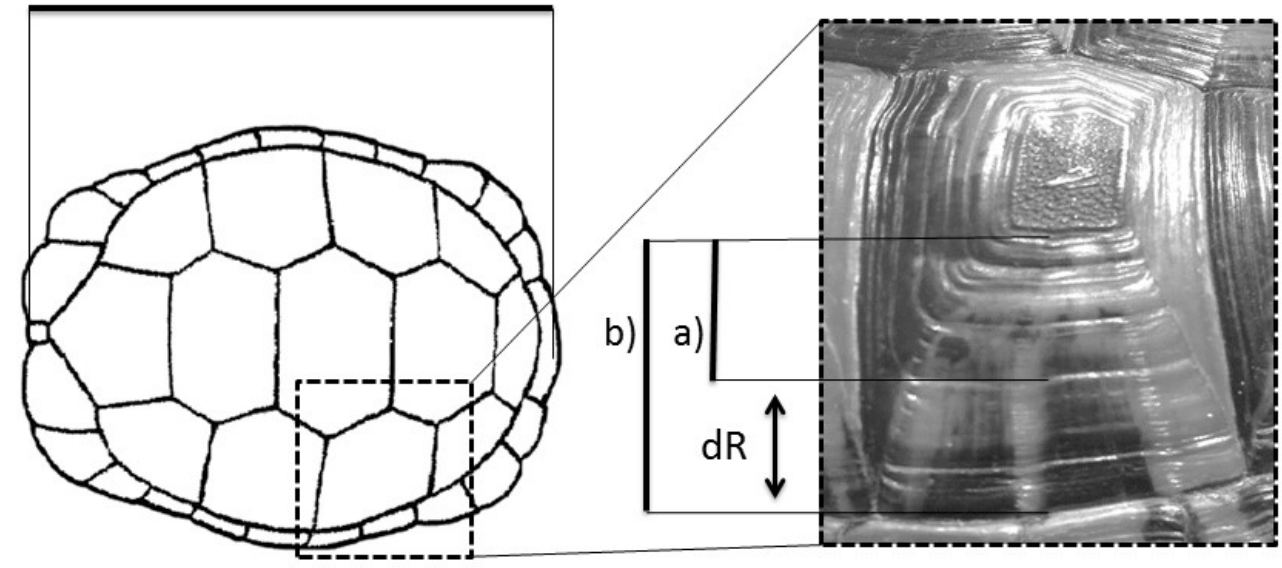

9 Figure A3. Example of number of rings and measure of the carapace length (CL) from

12 For tortoises older than 10 years old, we calculate their age using an inverse regression

13 by the equation 1 of Von Bertalanffy Model (Fabens, 1965) from Rodríguez-Caro et al. 14 (2013).

$16 \mathrm{~S}_{\infty}$ is asymptotic size, $b$ is a parameter associated with the amount of growth remaining,

$17 k$ is the growth rate, $t$ is the age of the individual and CL is the size (carapace length). We 


\begin{tabular}{cccc}
\hline Sex & $\mathrm{S}_{\infty}$ & $b$ & $k$ \\
\hline Females & 156.26 & -0.7843 & 0.145 \\
Males & 118.23 & -0.7112 & 0.228 \\
\hline
\end{tabular}

used the inverse of eq. 1 to calculate $\mathrm{t}$ (age of the tortoises) using CL (Rodriguez-Caro et al. 2013; table S1.1)

Table A2. Values of the parameters of Von Bertalanffy model according to RodriguezCaro et al. (2013) for males and females.

\section{3}

24

When the tortoises are older than 26 years old, the growth of the individual is asymptotic. Thus, estimate the age when the tortoises are older than 26 is impossible by this method. Therefore, we categorized all individuals in the last group (more than 25 years old).

\section{References}

Fabens A.J. (1965) Properties and fitting of the von Bertalanffy growth curve. Growth 29, 265-289.

Rodríguez-Caro R.C., Graciá E, Anadón JD \& Giménez A. (2013) Maintained effects of

3 fire on individual growth and survival rates in a spur-thighed tortoise population.

34 European Journal of Wildlife Research, 59: 911-913

3 Rodríguez-Caro, R.C., Graciá, E, Morais Dos Santos, R. Anadón, J.D. \& Gimenez, A. (2015) One scute ring per year in Testudo graeca? A novel method to identify ring deposition patterns in tortoises. Acta Herpetologica, 10(2): 77-84 


\section{Appendix 4}

3 We used the Distance Sampling method (Thomas et al., 2010) to calculate the detectability of the

4 individuals. This method assumes that detectability decreases as a function of the perpendicular

5 distance from the line and it uses the observed distances to model the detection function. We use

6 the same 153 individuals captured in 2003. The detection function was fitted to the distance data

7 using Distance 6.0 (Thomas et al. 2010). Upon preliminary inspection of the fit, we removed

8 perpendicular distances beyond $4.25 \mathrm{~m}$ (truncation distance, hereinafter $\omega$ ) where detection

9 probabilities generally fell to 0.1 or lower (Buckland et al. 2001). Due to the observers' tendencies

10 to round distances, we grouped the detections into five distance intervals (cutpoints: $0,0.75,1.5$,

$112.25,3.25,4.25 \mathrm{~m}$ ), similar to other studies (Rodríguez-Caro et al., 2017). We evaluated the fits of

12 the half-normal (HN) with multiple covariate distance sampling techniques (MCDS) including

13 STAGE as a covariate (three factors: juvenile, subadults and adults). We found that the detection

14 probability was 0.47 for adults, 0.41 for subadults and 0.27 for juveniles. Our results are similar to

15 previous studies (Rodriguez-Caro et al., 2016, 2017)

16

\section{References}

18 Buckland, S.T., Anderson, D.R., Burnham, K.P., Laake, J.L., Borchers D.L. \& Thomas L. (2001)

19 Introduction to Distance Sampling. Oxford University Press, Oxford.

20 Thomas, L., Buckland, S.T., Rexstad, E.A., Laake, J.L., Strindberg, S., Hedley, S.L., Bishop, J.R.,

21 Marques, T.A. \& Burnham, K.P. (2010) Distance software: design and analysis of distance

22 sampling surveys for estimating population size. Journal of Applied Ecology 47:5--14 
1 Rodríguez-Caro, R.C., Lima, M., Anadón, J.D., Graciá, E., \& Giménez, A. (2016) Density

2 dependence, climate and fires determine population fluctuations of the spur-thighed tortoise

3 Testudo graeca. Journal of Zoology, 300(4), 265-273.

4 Rodríguez-Caro, R.C., Oedekoven, C., Graciá, E., Anadón, J.D., Buckland, S.T., Esteve Selma,

5 M.A. Martinez, J. \& Giménez, A. (2017). Low tortoise abundances in pine forest plantations in

6 forest-shrubland transition áreas. PLoS ONE. 12(3): e0173485. 
Appendix 5

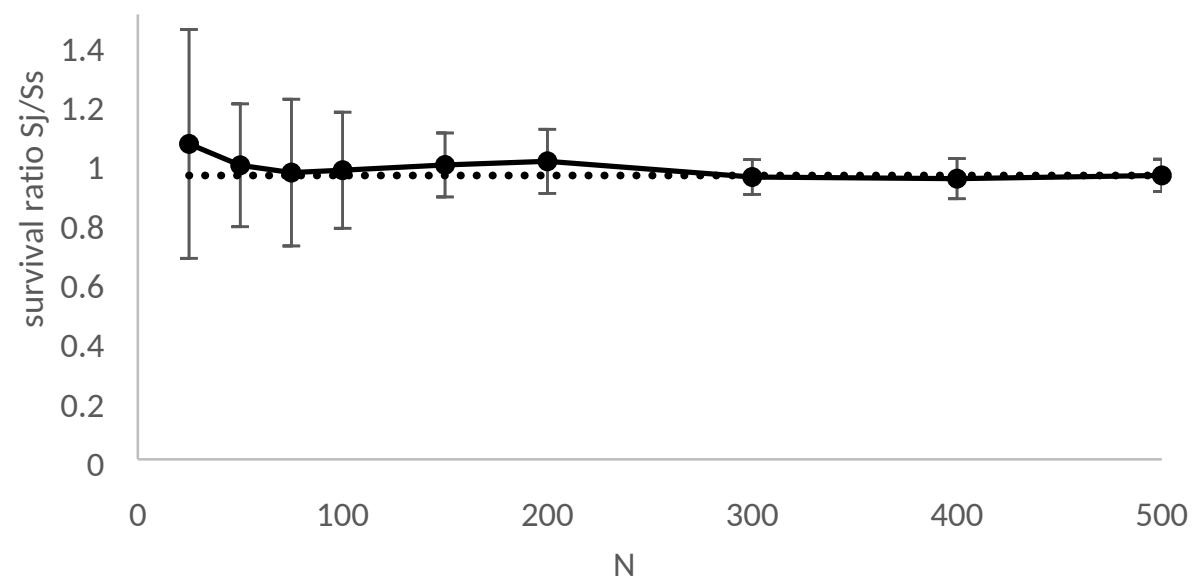

2

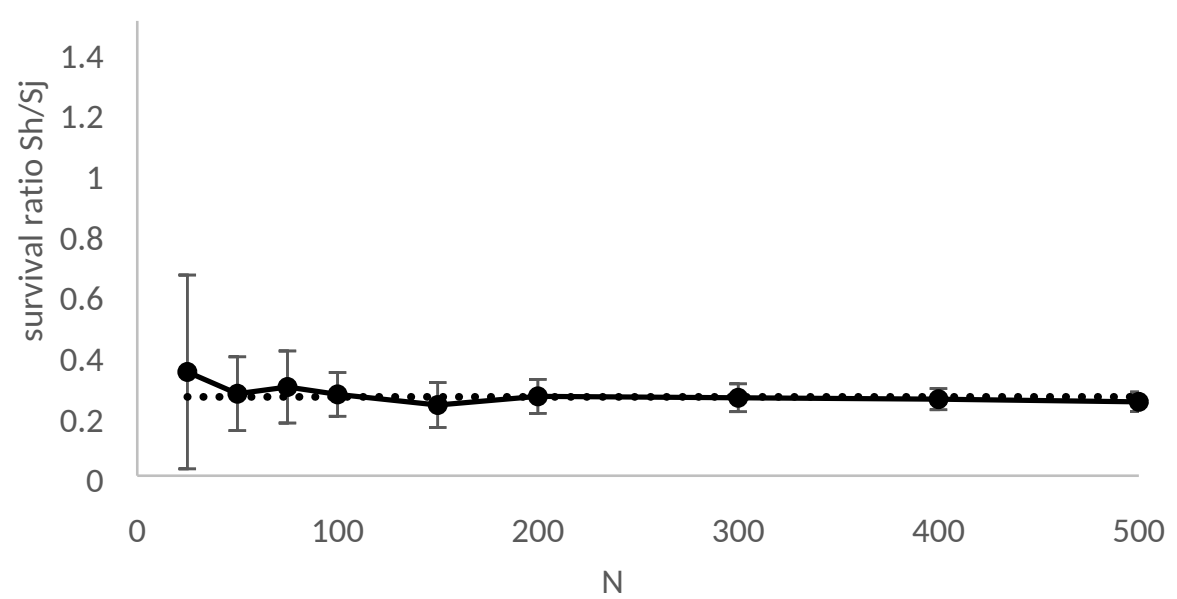

3

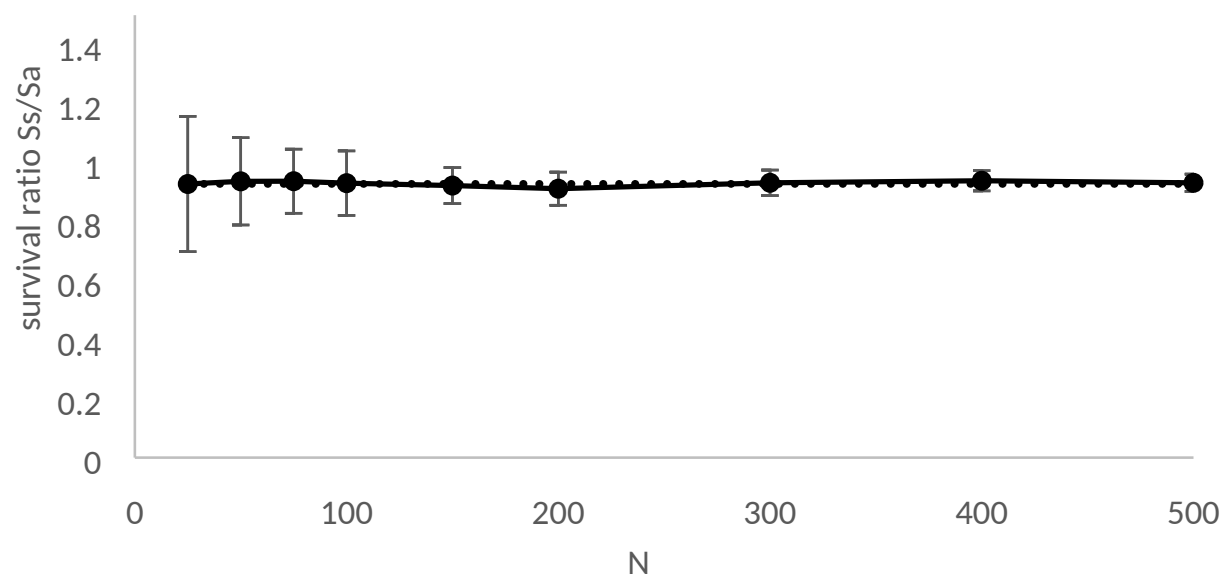


1 Figure A6. Number of individuals in the simulation $(\mathrm{N})$ and the estimate relative survival rates

2 (black lines) and their standard simulations between simulations. Black dotted lines are the

3 known relative survivals rates.

4 